\title{
LA EQUIDAD COMO VALOR DEL ORDEN PÚBLICO EUROPEO Y SU APLICACIÓN EN ASUNTOS TRANSFRONTERIZOS DE DERECHO DE FAMILIA*
}

\author{
EQUITY AS A VALUE OF EUROPEAN PUBLIC POLICY \\ AND ITS APPLICATION IN CROSS-BORDER MATTERS \\ OF FAMILY LAW
}

\author{
María Jesús SÁnchez CANo \\ Profesora de Derecho Internacional privado \\ Universidad San Jorge \\ Romina Santillán Santa CRUZ \\ Profesora de Derecho Civil \\ Universidad Isabel I de Castilla
}

Recibido: 15.06.2021 / Aceptado: 09.07.2021

DOI: https://doi.org/10.20318/cdt.2021.6315

\begin{abstract}
Resumen: La creación de un orden público verdaderamente internacional es una aspiración que viene del siglo XIX. Ahora recibe un impulso muy relevante gracias al TEDH. Tanto el TEDH como el TJUE se han visto en la necesidad de reanalizar y unificar determinados conceptos propios del Derecho de familia a la hora de aplicar el CEDH y el Derecho de la Unión Europea, respectivamente. Esta situación ha venido motivada por la aparición, en el ámbito europeo, de unos nuevos modelos de familia, que, junto con otras instituciones, o bien resultan desconocidos en los ordenamientos jurídicos europeos, o bien sus efectos se regulan de forma diferente en esos órdenes legales desde los que, al menos en el plano fáctico, han sido importados. Todo lo cual, como se verá en este trabajo, nos permite sostener que la equidad actúa como un valor del orden público europeo, cuya aplicación ponderada se aprecia en las resoluciones de los tribunales europeos sobre asuntos transfronterizos de Derecho de familia.
\end{abstract}

Palabras clave: orden público internacional, Derecho de familia, equidad, TEDH, TJUE.

Abstract: The creation of a truly international public policy is an aspiration dating from the 19th century. Currently receives a very relevant boost thanks to the European Court of Human Rights. Both the European Court of Human Rights and the European Court of Justice have had to review and unify concepts specific to Family Law when implementing the European Convention on Human Rights and European Union Law, respectively. This situation has been motivated by the emergence, at the European level, of new family models, which, together with other institutions, are unknown in European Legal Systems, or its effects are regulated differently in those legal orders from which, at least at the factual

\footnotetext{
* Este trabajo ha sido realizado en el marco del Grupo Consolidado de Investigación del Gobierno de Aragón «Ius Familiae», IP. Carlos Martínez de Aguirre Aldaz, y del Proyecto de Investigación del Ministerio de Ciencia e Innovación PID2019105489RB-I00: «Vulnerabilidad patrimonial y personal: retos jurídicos», IIPP. Ma Victoria Mayor del Hoyo y Sofía de Salas Murillo.
} 
level, have been imported. All of which, as will be seen in this paper, allows us to maintain that equity acts as a value of the European public policy, whose pondered application is reflected in the decisions of the European Courts about cross-border matters of Family Law.

Keywords: international public policy, Family Law, equity, European Court of Human Rights, European Court of Justice.

Sumario: I. Estado de la cuestión. II. Consideraciones generales sobre la institución del orden público internacional. 1. Notas configuradoras del concepto de orden público internacional. 2. Orden público internacional y Derecho de la Unión Europea: su conexión con los derechos a la ciudadanía europea y a la libertad de circulación y residencia en el territorio de la Unión. 3. Convenio Europeo de Derechos Humanos y orden público internacional. III. Concepto de equidad: alcance y funciones. IV. Análisis de la jurisprudencia más emblemática dictada en el ámbito europeo. 1. Análisis de la jurisprudencia del TJUE. 2. Análisis de la jurisprudencia del TEDH. V. Recapitulación conclusiva.

\section{Estado de la cuestión}

1. La creación de un orden público verdaderamente internacional (común a varios Estados) es una aspiración que viene del siglo XIX. Ahora recibe un impulso muy relevante gracias al TEDH. En los últimos tiempos, tanto el TEDH como el TJUE se han visto en la necesidad de reanalizar y unificar determinados conceptos propios del Derecho de familia a la hora de aplicar, en el primer caso, el CEDH y, en el segundo, el Derecho de la Unión Europea. Esta situación ha venido motivada por la aparición, en el ámbito europeo, de unos nuevos modelos de familia (matrimonio entre personas del mismo sexo, relaciones de pareja estables, filiación por gestación por sustitución, etc.), que, junto con otras instituciones, o bien resultan desconocidos en los ordenamientos jurídicos europeos, o bien sus efectos se regulan de forma diferente en esos órdenes legales desde los que, al menos en el plano fáctico, han sido importados (kafala, adopción simple, adopción de mayores de edad, etc.).

2. Pero muy en particular se plantean problemas relacionados con el respeto a la vida privada y familiar (art. 8 CEDH y art. 7 CDFUE) y el derecho a la libre circulación y residencia (art. 21 TFUE y art. 45 CDFUE). Para la aplicación de estos preceptos al caso concreto, ha sido necesario matizar, entre otros, conceptos tales como "cónyuge", "vínculo de filiación", "vida familiar", "descendiente directo", "familiares y asimilados", en función del contexto y objetivos que se pretende alcanzar con las normas en las que se integran. Esto ha dado lugar a definiciones autónomas, independientes de las previstas en los ordenamientos de los Estados. El objetivo de esta operación de exégesis consiste, en la mayor parte de los casos, en garantizar la continuidad de las relaciones familiares en supuestos transfronterizos, frente a las limitaciones o restricciones establecidas por los poderes públicos de cada Estado.

3. En este sentido, respecto del art. $8 \mathrm{CEDH}$, es doctrina consolidada del TEDH que, a pesar de que los Estados disponen de un cierto margen de apreciación para verificar que no se ha producido una intromisión arbitraria, habrá que determinar si se ha alcanzado el justo equilibrio entre los intereses de un sujeto en particular y los de la sociedad en su conjunto. Para ello, el citado Tribunal ha precisado una serie de valores que pueden operar como límite a la excepción de orden público internacional, orientando y matizando la aplicación de esta excepción por los Tribunales de los Estados contratantes de la Convención.

4. Por su parte, el TJUE ha interpretado principios como el de no discriminación por razón de la nacionalidad, al mismo tiempo que ha completado el concepto de ciudadanía europea y los derechos que derivan de tales circunstancias, que se encuentran recogidos en diferentes Reglamentos y Directivas. Todo ello con el objeto de favorecer la libertad de circulación de los ciudadanos de la Unión Europea 
y asimilados, evitando el establecimiento de límites que, por ser poco ponderados, pudieran terminar comportando un obstáculo al ejercicio de dicha libertad. Todo ello, tomando en consideración también la existencia de un derecho a la vida privada y familiar, que, estando garantizado en la CDFUE y en el CEDH, podría verse afectado por posibles restricciones injustificadas al ejercicio de la mencionada libertad de circulación. Más aún cuando el Tribunal en cuestión, en determinados supuestos, ha constatado graves deficiencias con respecto a la salvaguarda del principio de igualdad y con la exigencia de aplicación uniforme del Derecho de la Unión Europea en todos los Estados miembros.

5. A la vista de las anteriores consideraciones, el presente trabajo abordará el análisis de la jurisprudencia más relevante del TEDH y del TJUE, desde la perspectiva del Derecho de familia, con una doble finalidad:

$1^{\mathrm{a})}$ Identificar y analizar la interpretación autónoma que han otorgado ambos tribunales a algunos conceptos tradicionales propios de las relaciones familiares, con el fin de inferir los principios, derechos y valores que han de ponderarse a la hora de reconocer o dar efectos a una situación transfronteriza de Derecho de familia.

$2^{\text {a }) ~ D i l u c i d a r ~ s i ~ t a l e s ~ p r i n c i p i o s ~ o ~ v a l o r e s, ~ t a l ~ y ~ c o m o ~ s o n ~ a p l i c a d o s ~ p o r ~ l o s ~ m e n c i o n a d o s ~ t r i b u n a-~}$ les, son susceptibles de conformar un orden público internacional familiar europeo, que opere como excepción frente a las resoluciones de los poderes públicos de los Estados miembros.

6. Y para su desarrollo formulamos los siguientes interrogantes: ¿Existe un Orden Público Internacional Europeo? De existir, ¿se impondría este frente a las reglas del Derecho Internacional privado y a los conceptos de Derecho sustantivo de cada Estado? ¿Subyace al Orden Público Internacional Europeo el valor de la equidad convirtiéndolo en una suerte de orden público internacional atenuado, que, en función de cada caso concreto, deba conciliar realidades jurídicas dispares en orden a alcanzar una solución de justicia material?

\section{Consideraciones generales sobre la institución del orden público internacional}

\section{Notas configuradoras del concepto de orden público internacional}

7. En primer término, parece oportuno destacar algunas consideraciones básicas que intervienen en la configuración del concepto de orden público internacional. En este sentido, deben señalarse los siguientes extremos:

$\left.1^{\circ}\right)$ El orden público internacional lo integran todos aquellos principios generales vigentes en un concreto sistema jurídico en el momento actual. Destaca aquí su carácter particular e individualizado, en tanto que es propio de cada Estado y difiere de un Estado a otro ${ }^{1}$.

$2^{\circ}$ ) En lo que respecta al ámbito europeo, el orden público internacional procede de diferentes fuentes: el Derecho de la Unión Europea y las normas de protección de los derechos humanos incorporadas en convenios internacionales, como el Convenio Europeo de Derechos Humanos de 4 de noviembre de 1950 (en adelante, CEDH). En este punto, hay que dejar bien sentada la distinción entre los principios básicos del Derecho de la Unión Europea, cuya interpretación corresponde al TJUE, y los valores que derivan del CEDH, cuya exégesis la lleva a cabo el TEDH.

$3^{\circ}$ ) Opera a modo de excepción. De acuerdo con ello, ante una situación privada internacional, quedará descartada la aplicación del Derecho extranjero designado por la norma de conflicto del foro cuando resulte contrario a los principios fundamentales de dicho país. En su

\footnotetext{
${ }^{1}$ Vid. A.L. Calvo Caravaca y J. Carrascosa González, Derecho Internacional Privado, Vol. I, Decimoctava Edición, Granada, Madrid, 2018, p. 340.
} 
lugar, se aplicará, por tanto, la ley del foro. El ordenamiento jurídico español contempla la excepción de orden público internacional en el art. $12.3 \mathrm{Cc}$., si bien también se encuentra recogida en diferentes instrumentos legales de la Unión Europea ${ }^{2}$ o Convenios internacionales, como es el caso de algunos instrumentos legales procedentes de la Conferencia de La Haya de Derecho Internacional privado ${ }^{3}$. Aquí cabría hacer una puntualización: por ley del foro hay que entender la ley del Estado cuyos tribunales están conociendo del asunto y, en consecuencia, no cabe hablar de lex fori en relación con el Derecho de la Unión Europea; más aún, teniendo en cuenta que en la materia que nos ocupa, que no es otra que la de las relaciones de familia transfronterizas, si bien disponemos de algunos instrumentos que distribuyen la competencia judicial internacional entre los Estados miembros, y de algunas normas de conflicto uniformes, lo cierto es que el Derecho de la Unión Europea no ha establecido normas de Derecho sustantivo comunes a los Estados miembros que regulen conceptos tales como "divorcio", "matrimonio", "relación de filiación", etc.

$4^{\circ}$ ) La función de la excepción del orden público internacional es proteger la "cohesión moral y jurídica", junto con la "identidad cultural" de la sociedad de un país o territorio, y la defensa de la "paz social"4.

$5^{\circ}$ ) La aplicación de la excepción tiene carácter restrictivo. Debido a ello, no caben respuestas generalizadas y abstractas, sino que habrá que estar al caso concreto. De ahí que se abogue por dejar de lado la rigidez, en favor de la flexibilización de la excepción de orden público, con la finalidad de encontrar soluciones materialmente justas para una institución y respecto de un supuesto específico 5 .

$\left.6^{\circ}\right)$ Enlazando con lo anterior, surge la tesis del "orden público internacional atenuado", en cuya virtud no cabe aplicar la cláusula de orden público internacional de forma plena - es decir, excluyendo la aplicación del Derecho extranjero designado por la norma de conflicto del país cuyos tribunales conocen del asunto y aplicando en su lugar el Derecho del forocuando la situación privada internacional se haya creado válidamente en el extranjero y con arreglo a dicho ordenamiento jurídico extranjero y siempre que sus efectos no resulten manifiestamente contrarios a los principios y valores esenciales de la sociedad cuyos tribunales conocen del asunto. Se trataría, entonces, no tanto de reconocer la situación en sí misma, sino tan solo determinados "efectos jurídicos periféricos" que traen causa de esa relación'.

\footnotetext{
${ }^{2}$ Todos los Reglamentos de la UE recogen cláusulas de orden público internacional como excepción a la aplicación de una ley extranjera manifiestamente contraria a los principios fundamentales del Estado miembro del foro. Como ejemplo, cabe citar el art. 20 del Reglamento (CE) No 593/2008 del Parlamento Europeo y del Consejo de 17 de junio de 2008 sobre la ley aplicable a las obligaciones contractuales (DOUE núm. 177, de 4 de julio de 2008) o el art. 12 del Reglamento (UE) No 1259/2010 del Consejo de 20 de diciembre de 2010 por el que se establece una cooperación reforzada en el ámbito de la ley aplicable al divorcio y a la separación judicial (DOUE núm. 343, de 29 de diciembre de 2010).

${ }^{3}$ La noción de orden público internacional presente en los Convenios de la Conferencia de La Haya es de interpretación restrictiva, toda vez que entra en juego únicamente en el caso de contrariedad manifiesta con los valores fundamentales del foro. A modo de muestra, se menciona el art. 22 del Convenio de 19 de octubre de 1996 Relativo a la Competencia, la Ley Aplicable, el Reconocimiento, la Ejecución y la Cooperación en materia de Responsabilidad Parental y de Medidas de Protección de los Niños, contempla una cláusula de orden público internacional (BOE núm. 291, de 2 de diciembre de 2010), o el art. 24 del Convenio relativo a la protección del niño y a la cooperación en materia de adopción internacional, hecho en La Haya el 29 de mayo de 1993 (BOE núm. 182, de 1 de agosto de 1995).

${ }^{4}$ Vid. A.L. Calvo Caravaca y J. Carrascosa González, Derecho Internacional Privado, cit., pp. 328 y ss. Siguiendo a estos autores, en este punto, hay que distinguir el orden público internacional del orden público interno o de las normas imperativas, de aplicación necesaria o de policía. Véase $O p$. cit., pp. 333 y 334.

${ }^{5}$ Así lo entiende Alegría Borrás cuando sostiene que "[l] integración en la sociedad del Estado de recepción no puede suponer la pérdida de valores culturales tradicionales y, por tanto, se trata de encontrar soluciones para las distintas instituciones". Vid. A. Borrás, "Europa multicultural. El caso de España. Introducción”, en A. Borras y S. Mernissi, El Islam jurídico y Europa. Derecho, religión y política, Barcelona, Icaria \& Antrazyt, 1998, p. 159. Ténganse en cuenta aquí, que lo que vulnera el orden público internacional es el resultado de la aplicación del Derecho extranjero en el caso concreto, en lugar de su contenido en abstracto. Además, el orden público internacional no se ve infringido por el solo dato de que una institución extranjera no se encuentre regulada en el Derecho del foro, ni tampoco porque su ordenación sea diferente. Vid. A.L. CALvo CARAvaCA y J. Carrascosa González (Dirs.), Compendio de Derecho Internacional Privado, Murcia, 2019, pp. 122-123.

${ }^{6}$ Vid. A.L. Calvo Caravaca y J. Carrascosa González, “Tema V: Derecho aplicable (II). Orden público internacional”, en
} 
$7^{\circ}$ ) En los últimos tiempos, un sector de la doctrina y de la jurisprudencia ha venido defendiendo lo que se conoce como el "orden público internacional de proximidad". Esta figura requiere que el supuesto de hecho en cuestión presente una mínima conexión con el Estado del foro, de modo que si la situación se encuentra alejada del mismo, la excepción del orden público internacional no debería operar. Ello, por cuanto la sociedad de dicho país no resulta afectada por la aplicación de un Derecho extranjero ${ }^{7}$.

\section{Orden público internacional y Derecho de la Unión Europea: su conexión con los derechos a la ciudadanía europea y a la libertad de circulación y residencia en el territorio de la Unión}

8. Sentadas las consideraciones anteriores, en primer lugar, respecto del Derecho de la Unión Europea, conviene recordar una serie de premisas ciertamente relevantes:

$1^{\text {a)}) ~ E l ~ o r d e n a m i e n t o ~ j u r i ́ d i c o ~ d e ~ l a ~ U n i o ́ n ~ E u r o p e a ~ e s ~ u n ~ o r d e n a m i e n t o ~ p r o p i o, ~ d i s t i n t o ~ d e l ~ d e ~}$ los Estados miembros.

$2^{\mathrm{a}}$ ) En virtud del principio de primacía del Derecho de la Unión Europea, este prevalece sobre los ordenamientos jurídicos de los Estados miembros y, por consiguiente, estos quedan supeditados a los principios fundamentales del Derecho de la Unión.

$3^{a}$ ) Desde esta perspectiva, los principios y valores esenciales del Derecho de la Unión Europea conforman también el orden público internacional de los Estados miembros ${ }^{8}$.

9. Pero, ¿cuáles son esos principios fundamentales presentes en el Derecho de la Unión y cómo inciden en las relaciones objeto del Derecho de familia y de la persona, tal como se regulan en el Derecho de los Estados miembros? Para dar respuesta a esta cuestión, parece oportuno comenzar analizando la proyección de los derechos fundamentales que integran el Derecho de la Unión como elemento coordinador de una suerte de orden público internacional supranacional en materia de Derecho de familia y de la persona.

10. A este respecto, debe advertirse que la protección de los derechos humanos en el ámbito europeo ha venido siendo progresiva9. Así, hay que partir del Derecho originario, y concretamente, de los Tratados constitutivos de la Comunidad Europea, cuya vocación puede calificarse básicamente como económica y de los cuales derivan las cuatro libertades fundamentales ${ }^{10}$.

11. Con posterioridad, los Tratados de integración y otros instrumentos remarcaron el respeto y promoción de los derechos fundamentales recogidos en las Constituciones de los Estados miembros, en

A.L. Calvo Caravaca y J. Carrascosa González (Dirs.), Compendio de Derecho Internacional Privado, cit., p. 155.

${ }^{7}$ El art. 23 LAI incorpora la teoría del orden público internacional de proximidad. Para mayor información sobre el orden púbico internacional de proximidad, véase: A.L. Calvo CaravaCa y J. CARrascosa GonzÁlez, "Derecho Internacional Privado y matrimonio entre personas del mismo sexo", Anales de Derecho, no 23, 2005, pp. 31-33; y, J. Rodríguez Rodrigo, "Problemas de aplicación regulados en el Reglamento sucesorio Europeo", Cuadernos de Derecho Transnacional, (Marzo 2019), Vol. II, $\mathrm{n}^{\mathrm{o}} 1$, p. 504

${ }^{8}$ Vid. A.L. Calvo Caravaca y J. Carrascosa González, Derecho Internacional Privado, cit., p. 342; y, N. Bouza Vidal, "La salvaguarda del orden público en los contratos internacionales: enfoque de derecho internacional privado y su adaptación en el derecho europeo", El orden público interno, europeo e internacional civil. Acto homenaje a la Dra. Nuria Bouza Vidal, Catedrática de Derecho internacional privado, InDret, Revista para el análisis del Derecho, Barcelona, Abril 2017, p. 81.

9 Vid. A. QuiÑones EsCÁMEZ, "Derecho comunitario, Derechos fundamentales y denegación del cambio de sexo y apellidos: ¿Un orcen público europeo armonizador? (a propósito de las SSTCE, asuntos K.B. y García Avello), Revista de Derecho Comunitario Europeo, Año 8, no 18, Mayo-Agosto 2004, p. 510.

${ }^{10}$ Libertad de circulación de mercancías, libertad de establecimiento y de prestación de servicios, libertad de circulación de trabajadores y libertad de circulación de capitales. 
el CEDH y en la Carta Social Europea ${ }^{11}$. De este modo, dado que los tratados dan prioridad a la realización de un espacio de libertad, seguridad y justicia, se hace hincapié en estos mismos valores, junto con el principio de no discriminación como principio general de la Unión, al mismo tiempo que se incorpora el concepto de ciudadanía europea. Cabe destacar aquí el derecho a la libre circulación y residencia de personas, recogido en el art. 21 TFUE, por su incidencia en las situaciones de Derecho Privado, y en particular, en las relaciones familiares ${ }^{12}$.

12. El proceso culmina con la Carta de Derechos Fundamentales de la Unión Europea de 2007 (CDFUE), en la cual se contempla el conjunto de derechos civiles, políticos, económicos y sociales de los ciudadanos europeos que vivan en el territorio de la Unión. En referencia a esta Carta, debe observarse que su art. 52.3 incorpora el principio de homogeneización en la interpretación del sentido y alcance de los derechos previstos en la Carta que se correspondan con los derechos garantizados en el CEDH y sus Protocolos, si bien permite que el Derecho de la Unión les otorgue una protección más extensa.

13. Sin olvidar que tales derechos han de ejercerse en las condiciones y con los límites comprendidos en los Tratados (art. 52.2 CDFUE), de lo anterior se infiere que la interpretación que realice el TJUE de los derechos que aparecen en la Carta de los Derechos Fundamentales de la Unión Europea ha de inspirarse, en su caso, en la Jurisprudencia del TEDH. De ahí la importancia del CEDH y de la doctrina del TEDH para establecer una hipotética existencia de un orden público internacional europeo.

14. Específicamente, resulta de interés para el presente trabajo ahondar en algunos puntos relacionados con el derecho a la libre circulación y residencia de todos los ciudadanos de la Unión Europea por el territorio de la Unión:

$1^{\circ}$ ) El fundamento del citado derecho a la libre circulación y residencia se sitúa en los arts. 3.2 y 21, así como en los títulos IV y V del Tratado de Funcionamiento de la Unión Europea (TFUE), junto al art. 45 de la Carta de los Derechos Fundamentales de la Unión Europea $(\mathrm{CDFUE})^{13}$.

$2^{\circ}$ ) Concretando más, deben ponerse en relación los arts. 18 y 21 TFUE. El primero de los preceptos citados contempla la prohibición de discriminación por razón de nacionalidad ${ }^{14}$. Mientras que, el segundo de ellos otorga la titularidad directa del derecho a la libre circulación y residencia a los ciudadanos de la Unión Europea, desarrollando lo dispuesto en el art. 20 TFUE, que define el concepto de ciudadanía europea y enuncia algunos de los derechos que derivan de esta circunstancia. Estos presupuestos se han venido completando a través

\footnotetext{
${ }^{11}$ Vid. "Declaración común del Parlamento Europeo, del Consejo y de la Comisión sobre los Derechos Fundamentales" (Luxemburgo, el 5 de abril de 1977) y "Acta Única Europea” (1996).

${ }^{12}$ Sobre este particular, hay que tener en cuenta que las primeras normas solo contemplaban la libre circulación de trabajadores y la libertad de establecimiento y venían recogidas en el Tratado constitutivo de la Comunidad Económica Europea (1.1.1, 2.1.5 y 2.1.4). El concepto de ciudadanía europea se incorporó en el Tratado de Maastricht, de tal manera que todos los nacionales de un Estado miembro son automáticamente ciudadanos de la Unión y, en consecuencia, son titulares del derecho a circular y residir libremente en el territorio de los Estados miembros. Por su parte, el Tratado de Lisboa, además de confirmar este derecho, lo incluyó en las disposiciones generales sobre el espacio de libertad, seguridad y justicia. Vid. Fichas temáticas sobre la Unión Europea. Parlamento Europeo. Libre circulación de personas, http://www.europarl.europa.eu/factsheets/es/ sheet/147/la-libre-circulacion-de-personas. Por lo que respecta a la evolución de esta cuestión en los diferentes Tratados, vid. M. Moya Escudero, "Un Código de derechos para los nacionales de terceros Estados residentes legales en la Unión: un avance en derecho antidiscriminatorio", Revista Electrónica de Derecho Internacional n ${ }^{\circ}$ 34, 2017.

${ }^{13}$ Vid. Fichas temáticas sobre la Unión Europea. Parlamento Europeo. Libre circulación de personas, http://www.europarl.europa.eu/factsheets/es/sheet/147/la-libre-circulacion-de-personas.

${ }^{14}$ El apartado 2 del art. 21 TFUE (art. 18 TCE) faculta a Parlamento Europeo y al Consejo "adoptar, con arreglo al procedimiento legislativo ordinario disposiciones destinadas a facilitar el ejercicio de los derechos [libre circulación y residencia]".
} 
de diferentes Reglamentos y Directivas ${ }^{15}$, así como mediante la jurisprudencia del TJUE, tal y como más adelante se estudiará ${ }^{16}$.

$3^{\circ}$ ) Aunque la titularidad del derecho a la libre circulación y residencia no corresponde a los nacionales de terceros Estados, el ejercicio de este derecho se ha hecho así mismo extensivo a los familiares de los ciudadanos de la Unión y asimilados, con el argumento de que favorece la libre circulación de los ciudadanos de la Unión, por lo cual el establecimiento de límites desproporcionados supondría un obstáculo a dicha libertad. Todo ello, unido a la salvaguarda del derecho a la vida familiar, que, recogido, entre otros textos, en el art. 7 CDFUE y el art. $8 \mathrm{CEDH}$, se ha traducido en que los familiares de los ciudadanos de la Unión son titulares de un derecho derivado a la libre circulación y residencia ${ }^{17}$.

15. Teniendo en cuenta lo que antecede, cabe cuestionarse si estos derechos fundamentales pueden constituir un orden público europeo y operar como excepción de orden público internacional. En este sentido, se ha indicado que podrían funcionar para limar las diferencias de los ordenamientos jurídicos de los Estados miembros en materia de orden público. Sin embargo, se duda de su aplicación directa a nivel internacional y, más bien, hay una tendencia a tener en cuenta otras variables, tales como la proximidad, los vínculos o el impacto que la situación pueda comportar en el territorio de la Unión. Es decir, parece defenderse la solución del orden público internacional de proximidad ${ }^{18}$.

16. La cuestión se abordará con mayor profundidad al estudiar la jurisprudencia del TJUE y del TEDH, en particular, por lo que respecta, por un lado, a los derechos de libertad de circulación y residencia en el territorio de la Unión y a la ciudadanía europea, y por otro, al derecho al respeto a la vida privada y familiar.

\section{Convenio Europeo de Derechos Humanos y orden público internacional.}

17. Se trata de un Convenio aprobado en el ámbito del Consejo de Europa, que se encuentra en vigor en los Estados miembros de la Unión Europea y al cual, como ya se ha explicado, la CDFUE otorga una importancia primordial. A esto se suma que el CEDH ha sido completado o matizado por diversos Protocolos.

18. Siguiendo a autores como Calvo Caravaca y Carrascosa González ${ }^{19}$, hay que destacar, como dato primario, que el CEDH incorpora un catálogo de derechos humanos sustantivos, los cuales deben

\footnotetext{
${ }^{15}$ En la actualidad, las condiciones para el ejercicio de la libertad de circulación y residencia, temporal o permanente, de los ciudadanos de la Unión Europea y de sus familiares se encuentran reguladas en la Directiva 2004/38/CE, relativa al derecho de los ciudadanos de la Unión y de los miembros de sus familias a circular y residir libremente en el territorio de los Estados miembros. La Directiva se aprobó después de la supresión de las fronteras interiores, de conformidad con el Acuerdo Shengen y unifica en un solo texto otros instrumentos legislativos. Esta norma define igualmente los límites de dichas libertades por razones de orden público, seguridad pública o salud pública, además de clarificar el régimen de los trabajadores por cuenta ajena, por cuenta propia, estudiantes o personas que no trabajen a cambio de una remuneración. Recuérdese que modifica el Reglamento (CEE) $n^{\circ}$ 1612/68 y deroga las Directivas 64/221/CEE, 68/360/CEE, 72/194/CEE, 73/148/CEE, 75/34/CEE, 75/35/CEE, 90/364/CEE, 90/365/CEE y 93/96/CEE. A este respecto, consúltese: Fichas temáticas sobre la Unión Europea. Parlamento Europeo. Libre circulación de personas, http://www.europarl.europa.eu/factsheets/es/sheet/147/la-libre-circulacion-de-personas.

${ }^{16}$ Vid. P. Jiménez Blanco, "Las libertades de circulación y de residencia de los miembros de la familia de los ciudadanos de la Unión Europea”, Diario La Ley, n 5771, Sección Unión Europea, 30 de Abril de 2003, Año XXIV, Ref. D-103, Editorial LA LEY (LA LEY 693/2003).

${ }^{17}$ Vid. P. JiMÉNEZ BlanCo, "Las libertades de circulación y de residencia..., cit.; y, P. JimÉnEz BlanCo, "Doble nacionalidad y derecho de residencia de los miembros de la familia del ciudadano de la Unión. Sentencia del Tribunal de Justicia de 14 de noviembre de 2017, asunto C-165/16: Lounes", La Ley Unión Europea, n 56, 28 de Febrero de 2018, Editorial Wolters Kluwer (LA LEY 1305/2018).

${ }^{18}$ Vid. A. QuiÑones EsCÁMEZ, "Derecho comunitario, Derechos fundamentales y denegación del cambio de sexo y apellidos: ¿Un orcen público europeo armonizador?..., cit., pp. 526-528.

${ }^{19}$ Para la redacción de este apartado se ha tomado especialmente en consideración, A.L. CAlvo Caravaca y J. CARrascosa GonZÁlez, Derecho Internacional Privado, cit., pp. 351-356.
} 
ser respetados por los ordenamientos jurídicos y las autoridades de los Estados contratantes, que están obligadas a su aplicación tanto a los casos enteramente nacionales como a los supuestos objeto de Derecho Internacional privado. Y por su carácter general, tales resultan de aplicación a todas las personas que se encuentren bajo la jurisdicción de los Estados partes (art. 1), en tanto que son los titulares de los derechos del CEDH.

19. El mayor inconveniente que suscita la aplicación del CEDH respecto a casos internacionales radica en que el Convenio no contempla mecanismo alguno de Derecho Internacional privado que garantice el respeto a los derechos humanos recogidos en el mismo. Por este motivo, ante un determinado supuesto con elemento internacional, se hace necesario el recurso a los métodos previstos en el ordenamiento jurídico del foro, lo que debe dar lugar a la puesta en práctica de la excepción del orden público internacional cuando la aplicación del Derecho extranjero designado por una norma de conflicto infrinja los derechos y libertades recogidos en el CEDH. Cuestiones tales que se han de valorar atendiendo a las circunstancias del caso concreto y a la vinculación del supuesto con el Estado parte de que se trate.

20. La aplicación del CEDH puede cumplir dos importantes objetivos:

$1^{\circ}$ ) La coordinación de los sistemas jurídicos de los Estados parte del Convenio y la eliminación de la aplicación "imperialista" del orden público internacional del foro, que no debe afectar la regulación de una sociedad extranjera.

$2^{\circ}$ ) La estabilidad de las relaciones jurídicas establecidas legalmente por los particulares, con la consiguiente seguridad jurídica que ello proporciona. Aquí se aboga nuevamente por el orden público internacional de proximidad como solución más razonable, en particular, en lo referente al reconocimiento de decisiones extranjeras que tienen por objeto situaciones válidamente constituidas en un Estado y cuya eficacia se solicita en otro Estado diferente.

21. En un epígrafe posterior, se estudiará cómo esta estabilidad y continuidad de las situaciones jurídicas ha sido abordada por el TEDH, que ha centrado una especial atención en el art. $8 \mathrm{CEDH}$, que regula el derecho al respeto a la vida personal y familiar, y otra muy en particular, en instituciones del Derecho de familia como la adopción, la kafala de Derecho islámico y la filiación a través de la gestación subrogada.

\section{Concepto de equidad: alcance y funciones}

22. Como podrá recordar el lector, planteando como hipótesis general la posible existencia de un orden público internacional europeo, en la parte introductoria de este trabajo hemos formulado si ¿subyace al Orden Público Internacional Europeo el valor de la equidad convirtiéndolo en una suerte de orden público internacional atenuado, que, en función de cada caso concreto, deba conciliar realidades jurídicas dispares en orden a alcanzar una solución de justicia material?

23. La razón que nos conduce a preguntarnos la cuestión que antecede reside en la naturaleza misma de las cosas. La experiencia de estos últimos tiempos nos muestra que los diferentes tribunales europeos han empezado a inclinarse por la línea de un espectro conciliador del orden público europeo en materia de familia. En función de la mayor o menor vulnerabilidad que comporte la situación de que se trate para los sujetos afectados, el orden público europeo tendería a flexibilizar la aplicación de la ley designada por la norma de conflicto para corregir la situación litigiosa, adecuándola según sea el caso, y evitar que la afectación se intensifique. Y este no sería otro que aquel a que hemos venido a denominar "orden público internacional atenuado". 
24. La tendencia es atemperar las situaciones enjuiciadas e intentar conciliarlas sin imponer nada a los Estados contratantes, cuya función habilitadora permanecerá solo en el plano de los efectos, es decir, de la eficacia de las resoluciones judiciales, pues la finalidad última de las medidas adoptadas es facilitar la libre circulación de las personas en todo el espacio europeo y, en consecuencia, procurar el libre desarrollo de la personalidad de todos los que lo ocupamos, sea cual fuere el derecho que se afecte. Esto solo puede ser posible en virtud de ese valor que es conocido bajo el nombre de equidad. Una equidad que, según entendemos, se encontraría en la base del orden público internacional europeo. Siendo necesario, para una mejor comprensión de este planteamiento, abordar brevemente el concepto de equidad con el objeto de determinar su alcance y funciones.

25. La equidad, de acuerdo con la doctrina clásica, entra en la esfera de la justicia, y más concretamente, en la de la justicia legal — que se mide por la adecuación o perfecta coincidencia entre lo mandado por las leyes imperativas y lo efectivamente cumplido ${ }^{20}$ - Se define a la equidad como la justicia matizada o atenuada por otras virtudes, como la solidaridad, por ejemplo ${ }^{21}$. Esto es así porque en el contexto general de las relaciones humanas y del "bien común" —que es objeto de la justicia legal, es decir, del cumplimiento o aplicación de las leyes - la justicia no puede ser contemplada aisladamen$t^{22}$. Y como consecuencia de ese proceso de armonización de la justicia con otras virtudes aparece lo equitativo, que es, precisamente, el objeto de la equidad. Lo equitativo constituye, en este escenario, el resultado de armonizar los deberes de justicia con los deberes correspondientes a otras virtudes ${ }^{23}$.

26. En conexión con lo anterior, también se habla de la equidad como justicia en su aplicación al caso concreto ${ }^{24}$. Bajo esta premisa, la "[e]quidad es todo lo contrario de una idea general; es más bien un catalizador dirigido a un resultado concreto que sea lo más acorde posible con la Justicia, dirigida a la determinación más justa posible del caso"25. Pero cabe matizar esta afirmación para una correcta comprensión de la relación entre equidad y justicia. La equidad tiene como función mejorar la justicia en el caso concreto para así favorecer, al propio tiempo, el bien común. De ahí que si, con la intención de lograr su pretensión, la equidad terminase destruyendo la justicia o entorpeciendo el bien común, no habría equidad sino injusticia.

27. La equidad está llamada a cumplir dos funciones: por un lado, atempera el deber, y por otro, acomoda el derecho ${ }^{26}$.

$1^{\circ}$ ) En cuanto a la primera función, la atemperación de lo debido consiste en rebajar, atenuar o dulcificar las exigencias de justicia, o si se quiere ser más específico, de lo ordenado por la norma - en el caso de la justicia legal—, y puede responder a diversas causas. Así, por ejemplo, esta atemperación, algunas veces, puede tener su causa en la solidaridad, en cuya virtud se produce la moderación necesaria para que el rigor de la justicia no dañe otros valores no menos importantes. Siendo el juez uno de los sujetos sobre quien recae la obligación de actuar con equidad ${ }^{27}$, cuando así sea preciso.

$2^{\circ}$ ) En la segunda función, esto es, la acomodación del derecho, la equidad se va a centrar, ya no en la deuda de justicia, sino en el derecho, buscando por todos los medios posibles su satisfacción en orden a procurar el bien del titular del derecho. Otras veces, sin embargo, la

\footnotetext{
${ }^{20}$ Cfr. J. Hervada, Introducción Crítica al Derecho Natural, Universidad de Piura, Piura, 1999, p. 80.

${ }^{21}$ Cfr. J. Hervada, Lecciones propedéuticas de filosofía del derecho, Tercera Edición, EUNSA, Pamplona, 2000, p. 249.

${ }^{22}$ Cfr. Ibídem, p. 248.

${ }^{23}$ Cfr. Ibídem, p. 249.

${ }^{24}$ Cfr. M.A. JÁureguI, "Equidad como principio: una interpretación de su contenido”, Ciencias Económicas. Universidad Nacional del Litoral, Vol. 2, n 14,2017, p. 107.

${ }_{25}$ J.B. Vallet de Goytisolo, Metodología de la determinación del Derecho, Editorial Universitaria Ramón Areces, Madrid, 1994, p. 1439.

${ }^{26}$ Cfr. J. Hervada, Lecciones propedéuticas de filosofia del derecho, cit., p. 249.

${ }^{27}$ Cfr. Ibídem.
} 
intención solo será disminuir, a la mínima expresión, los eventuales perjuicios que podría sufrir el justiciable ${ }^{28}$.

28. Las ideas que preceden nos permiten aproximarnos, entonces, a una premisa general fundamental en la materia: la justicia es la regla, y la equidad solo una excepción - y en esto, adelantamos, ya se identifica esta última con el "orden público internacional atenuado"-. La justicia hace posible el orden social justo, ese orden en que cada quien disfruta efectivamente de sus derechos o los ejerce sin interferencias, y, por ello, es la justicia la que siempre ha de actuar, la que estará en constante operatividad. No siempre se aplicará la equidad, porque esta solo es posible en determinados casos, siendo las particularidades de cada uno de estos las que servirán de guía preceptiva para determinar si debe actuarse o no con equidad. Por lo que, cuando esta se aplique entenderemos que la justicia sigue estando presente, pero en su versión atemperada o reforzada. "La Equidad no es la totalidad de la Justicia sino una parte de la misma, vale decir, una participación al caso concreto, como producto de aquella tarea de la Razón Práctica"29, que es la que debe orientar la decisión del juez.

\section{Análisis de la jurisprudencia más emblemática dictada en el ámbito europeo}

29. Tal como se ha expuesto al enunciar el estado de la cuestión, en esta instancia corresponde ya realizar el estudio de la jurisprudencia europea, para verificar si de la interpretación que lleva a cabo de determinadas nociones de Derecho de familia pueden extraerse principios y valores susceptibles de conformar un orden público europeo, que operaría en relaciones transfronterizas. Aunque cabe reiterar que, sea como fuere, al referirnos al orden público europeo, en ningún caso cabría confundir los principios que derivan del CEDH 1950 y los que traen causa del Derecho de la UE.

30. Por ello, este apartado se dividirá en dos epígrafes. En el primero de ellos se examinarán aquellas resoluciones del TJUE, que, particularmente, tienen por objeto el derecho a la libertad y residencia de los ciudadanos de la Unión, junto con el principio de ciudadanía europea y la prohibición de discriminación. El segundo epígrafe, por su parte, recogerá las consecuencias más relevantes que pueden extractarse de la jurisprudencia del TEDH a la hora de interpretar el art. $8 \mathrm{CEDH}$.

\section{Análisis de la jurisprudencia del TJUE}

31. A este respecto, han sido muchas las sentencias que han ido modulando el régimen de la libre circulación y residencia en relación con la prohibición de discriminación. Entre otras, cabe mencionar algunas de las resoluciones más significativas que se dictaron sobre la materia en cuestión, como la Sentencia del Tribunal de Justicia de 12 de mayo de 1998, Asunto C-85/96 - Martínez Sala (ECLI:EU:C:1998:217), y la Sentencia del Tribunal de Justicia de 17 de septiembre de 2002, Asunto C-413/99 - Baumbast y R (ECLI:EU:C:2002:493).

32. La ciudadanía europea y la libre circulación también fueron invocadas por este Tribunal en relación con el derecho al nombre, en la STJUE (Pleno) de 2 de octubre de 2003, Asunto C-148/02García Avello (ECLI:EU:C:2003:539) y STJUE (Gran Sala) de 14 de octubre de 2008, Asunto C-353/06 - Grunkin y Pau (ECLI:EU:C:2008:559).

33. Mucho más interesantes resultan, a los efectos del presente trabajo, los pronunciamientos que ha realizado más recientemente el TJUE al hilo del art. 2.2. de la Directiva 2004/38/CE. Y en consonancia con ellos, ha dictaminado que también quedan comprendidos en su ámbito de aplicación los

\footnotetext{
${ }^{28}$ Cfr. Ibídem, pp. 249 y 250.

${ }^{29}$ J.R. Pierpauli, “Algunas observaciones en torno del concepto de equidad”, Verbo, nº 375-376, 1999, p. 517.
} 
cónyuges del mismo sexo [STJUE (Gran Sala) de 5 de junio de 2018, Asunto C-673/16 - Coman y otros (ECLI:EU:C:2018:385)]. De la citada resolución se desprenden varias conclusiones relevantes ${ }^{30}$ :

$1^{\text {a) }}$ Las legislaciones de los Estados miembros pueden regular o no el matrimonio del mismo sexo e incluso no admitirlo, si bien, en el ejercicio de sus competencias no pueden vulnerar la libertad de circulación que corresponde a todos los ciudadanos de la UE.

$2^{a}$ ) Cabe la posibilidad de que, en casos justificados, un Estado miembro haga valer su excepción de orden público internacional para impedir el libre ejercicio del derecho a la libertad de circulación, siempre y cuando se acredite la existencia de grave riesgo para los intereses generales de la sociedad. Ello supone que el Estado miembro de destino no tiene ninguna obligación de reconocer ni otorgar plenos efectos constitutivos a un matrimonio entre personas del mismo sexo válidamente celebrado en el Estado de origen. Ahora bien, cosa distinta es que el Estado de destino reconozca la existencia de este matrimonio y la condición de cónyuge de un ciudadano de un tercer Estado, a los solos efectos de conceder un derecho de residencia derivado a un nacional de un tercer Estado, en tanto que no se conculque con ello el orden público internacional del Estado de destino.

$3^{\mathrm{a}}$ ) De la sentencia parece deducirse que el TJUE, siguiendo la doctrina del TEDH, asienta la idea de que existe un derecho a la continuidad de las relaciones de familia o atinentes al estado civil de las personas en supuestos transfronterizos. Ello, sobre la base del derecho al respeto de la vida privada y familiar, reconocido tanto en el art. 7 CDFUE como en el art. 8 CEDH.

$\left.4^{\circ}\right)$ En lo que se refiere a esta sentencia, hay que llegar a la conclusión de que no tiene como propósito obligar a los Estados miembros a garantizar la libre circulación de los «matrimonios» como institución jurídica. Antes bien, al contrario, lo que en verdad pretende el TJUE es salvaguardar el derecho a la libre circulación de personas.

34. En este sentido, cabe traer también a colación la STJUE de 26 de marzo de 2019, Asunto C 129/18, SM/Entry Clearance Officer, UK Visa Section (ECLI:EU:C:2019:248) ${ }^{31}$. La cuestión prejudicial resuelta en la mencionada resolución se centraba en dilucidar si podía considerarse un "descendiente directo", en el sentido del art. 2, apartado 2, letra c) de la Directiva 2004/38, al menor que se halla bajo la tutela legal permanente de un ciudadano o ciudadanos de la Unión con arreglo a la institución de la kafala o a una disposición equivalente prevista en la legislación de su país de origen. De esta sentencia cabe inferir las siguientes conclusiones:

$1^{\text {a) }}$ El Tribunal de Justicia, atendiendo al principio de igualdad y a la exigencia de aplicación uniforme del Derecho de la Unión, sostuvo que el término "descendiente directo" debe ser objeto de una interpretación uniforme en todo el territorio de la Unión ${ }^{32}$.

$2^{\mathrm{a}}$ ) En este punto, no debe olvidarse que el propósito de esta norma consiste en favorecer la libre circulación de los ciudadanos de la Unión por todo el territorio de la Unión Europea, principio este que se encuentra recogido en el art. 21 TFUE y que se vería conculcado de establecer obstáculos desproporcionados a su ejercicio. Como tampoco puede desconocerse que con esta finalidad se ha hecho extensiva dicha libertad a otros sujetos, como los mencionados en el art. 2.2 de la Directiva, dado que, de este modo, se reconoce la continuidad

\footnotetext{
${ }^{30}$ Sobre las implicaciones en materia de Derecho Internacional privado que contiene esta sentencia, consúltese J. CARRASCOSA GonZÁLEZ, "Libre circulación de personas, matrimonios entre personas del mismo sexo y la sentencia del TJUE de 5 junio 2018 en el asunto Coman-Hamilton", http://accursio.com/blog/?p=85; y, M. GUZMÁN ZAPATER, "Matrimonio entre personas del mismo sexo y derecho a la libertad de circulación (sobre la STJ, Gran Sala, 5 de junio de 2018, en el As.C-673/16, Coman)", Crónica de Derecho Internacional Privado, Revista Electrónica de Estudios Internacionales, 2018, www.reei.org.

${ }^{31}$ A mayor abundamiento, Vid. M.J. SÁnChez CANO, "La aplicación de la Directiva 2004/38/ce en supuestos de kafala (كفالة) internacional”, Cuadernos de Derecho Transnacional, Vol. 12, no 1, Marzo 2020, pp. 713-727.

${ }^{32}$ Acoge aquí el TJUE la doctrina de la Sentencia del Tribunal de Justicia (Gran Sala) de 21 de diciembre de 2011, asuntos acumulados C-424/10 y C-425/10 (ECLI:EU:C:2011:866). También ha sido utilizado este principio en el Asunto, C-673/16Coman, antes mencionado.
} 
de la relación familiar, ante la hipótesis de que estas personas quieran seguir al ciudadano de la Unión a otro Estado miembro o reunirse con él en dicho Estado.

$3^{a}$ ) El Tribunal de Justicia deja bien sentado que "no puede considerarse que un menor que se halla bajo la tutela legal de ciudadanos de la Unión con arreglo a una kafala sea 'descendiente directo' de un ciudadano de la Unión", habida cuenta que esta figura no crea un vínculo de filiación entre el kafil y el makfoul ${ }^{33}$. Sin embargo, el Tribunal de Justicia opta por dar respuesta a la solución litigiosa recurriendo a otro precepto de la Directiva, cual es el art. 3.2. a), salvaguardando, de este modo, tanto el principio del interés superior del menor ${ }^{34}$ como la unidad y continuidad familiar a la que se ha aludido con anterioridad y que, como se viene afirmando, es uno de los objetivos de la Directiva relativa a la libre circulación. Entiende, por tanto, el Tribunal que la situación puede entrar en el ámbito de aplicación del art. 3.2 a), toda vez que la menor SM puede considerarse como "otro miembro de familia", que se encuentra, en virtud de la kafala, decretada en el país de origen de la niña, a cargo de un ciudadano de la Unión que es beneficiario del derecho de residencia con carácter principal.

$\left.4^{\circ}\right)$ No obstante todo ello, ordena ponderar también en cada supuesto examinado la concurrencia de peligro o riesgo de que los menores tutelados puedan ser víctima de abuso, explotación o tráfico, motivo por el cual no descarta que los Estados miembros puedan efectuar los controles que estimen convenientes.

$5^{\circ}$ ) La conclusión más destacada a la que llega el Tribunal, a los efectos del presente trabajo, es que, si queda demostrada la existencia de una vida familiar efectiva y de una relación de dependencia entre el menor y su tutor, los Estados miembros, dando cumplimiento al principio del interés del menor y al derecho a la vida familiar, deberán conceder al menor el derecho de entrada y residencia, con la finalidad de que pueda convivir con su tutor en el Estado miembro de la residencia de este. Esta solución resulta acorde con lo dispuesto en los arts. 7 y 24 CDFU, en relación con el Considerando 31 de la Directiva, y en el art. 8 CEDH, así como con la jurisprudencia del TEDH.

\section{Análisis de la jurisprudencia del TEDH}

35. No debe olvidarse que la finalidad del art. 8 de la Convención es la protección del individuo frente a las intromisiones arbitrarias de los poderes públicos, para lo cual debe verificarse el equilibrio necesario entre los intereses del sujeto y los de la sociedad en su conjunto, si bien el Estado dispone de un cierto margen de apreciación ${ }^{35}$.

36. En este orden de consideraciones, y por lo que respecta a una supuesta violación del derecho a la vida privada y familiar, hay que recordar que el TEDH ha abordado en numerosas resoluciones la problemática de la adopción internacional ${ }^{36}$, construyendo una línea jurisprudencial de alcance general,

\footnotetext{
${ }^{33}$ Vid. M. Vargas Urrutia, “Capítulo XX. La kafala del Derecho musulmán y el Tribunal Supremo”, en A.L. Calvo Caravaca y J. Carrascosa GonzÁlez (Dirs.), El Tribunal Supremo y el Derecho Internacional Privado, Vol. 2, Colección "Derecho y Letras" no 1, Murcia, 2019, pp. 484-487. Destaca un sector doctrinal que, de no haber recurrido el TJUE a una interpretación autónoma y uniforme del concepto de "descendiente directo", se hubiera corrido el riesgo de que, a la luz del Derecho nacional, algún Estado miembro hubiera considerado que los menores en situación de kafala efectivamente son "descendientes directos" del ciudadano en cuestión, pudiendo dar lugar a interpretaciones diferentes en otros Estado miembros, lo que restringiría la libertad de circulación de aquellos ciudadanos que fuesen objeto de un trato desigual. Vid. N. Marchal Escalona, "La kafala, ciudadanía de la unión y los derechos fundamentales del menor: de Estrasburgo a Luxemburgo", La Ley Unión Europea, n 71, 30 de Junio de 2019 (LA LEY 7510/2019).

${ }^{34}$ El TJUE ha tomado en consideración el principio del interés del menor en numerosas sentencias. Por todas, Vid. Sentencia del Tribunal de Justicia (Gran Sala) de 10 de mayo de 2017, Asunto C-133/15 - Chavez-Vilchez y otros (ECLI:EU:C:2017:354).

${ }^{35}$ Téngase en cuenta la argumentación del TEDH en la STEDH de 3 mayo 2011, Caso Négrépontis-Giannisis contra Grecia (TEDH 2011/43).

${ }^{36}$ Vid. las SSTEDH de 22 enero 2008, Caso E.B. contra Francia (TEDH 2008/4); 13 enero 2009, Caso Todorova contra Italia (TEDH 2009/8); 10 enero 2008, Caso Kearns contra Francia (TEDH 2008/5); o de 13 septiembre 2007, Caso Emonet y otros contra Suiza, entre otras muchas.
} 
que bien puede operar a la hora de interpretar el significado y contenido del derecho a la vida privada y familiar del art. 8 del Convenio, en relación con el reconocimiento de una adopción extranjera ${ }^{37}$. Dicha corriente jurisprudencial se inclina por evitar situaciones familiares claudicantes derivadas de la diversidad legislativa de los Estados, flexibilizando la aplicación de la excepción del orden público internacional, cuya interpretación deberá realizarse de forma restrictiva, procurando el justo equilibrio entre los distintos intereses concurrentes, pero sin olvidar tampoco que, en materia de adopción, el interés prevalente es siempre el del menor.

37. En efecto, en este sentido, es doctrina jurisprudencial sentada del TEDH que, aunque la citada disposición "tiende en lo esencial a prevenir al individuo contra injerencias arbitrarias de los poderes públicos, no se limita a exigir al Estado que se abstenga de dichas injerencias", sino que "pueden añadirse otras obligaciones positivas inherentes al «respeto» efectivo de la vida familiar". Así, en todo caso, a juicio del TEDH, "debe tenerse en cuenta el equilibrio justo a mantener entre los intereses concurrentes de la persona y de la sociedad en su conjunto", de la misma manera que, en ambas hipótesis, "el Estado goza de cierto margen de apreciación" $"$.

38. En la misma medida, el Tribunal ha establecido que la noción de "vida privada", en el sentido del art. 8 del Convenio, "es un concepto amplio que comprende, entre otros, el derecho a entablar $y$ desarrollar relaciones con sus semejantes" 39 , el derecho al "desarrollo personal" la autodeterminación como tal" 41 , abarcando también "elementos tales como el nombre" "'42 "la identificación sexual, la orientación sexual y la vida sexual"43, así como "el derecho al respeto de la decisión de tener o no tener un hijo" ${ }^{4}$.

39. Igualmente y tratándose de un supuesto relacionado con la institución adoptiva, el TEDH tiene declarado que "el derecho a la adopción no figura como tal entre los derechos garantizados por el Convenio" 45 , lo que no excluye, según el Tribunal, "que los Estados partes en el Convenio puedan hallarse, en ciertas circunstancias, en la obligación positiva de permitir la formación y desarrollo de unos vínculos familiares legales" ${ }^{\prime 4}$. Más concretamente, en este punto, el Tribunal se ha pronunciado en el sentido de que "el derecho al respeto de una vida familiar presupone la existencia de una familia y no protege el mero deseo de fundar una" "47, si bien, hay que decir que, en ocasiones, el TEDH ha dejado abierta la cuestión de si el derecho a adoptar entraba o no en el ámbito de aplicación del art. 8 considerado aisladamente ${ }^{48}$.

40. No obstante lo dicho, lo determinante es que, conforme a su jurisprudencia, el Tribunal ha señalado de forma reiterada que "la cuestión de la existencia o no de una "vida familiar» es ante todo una cuestión de hecho, que depende de la existencia de unos estrechos vínculos personales" ${ }^{49}$.

${ }^{37}$ Vid., por ejemplo, la STDH de 28 junio 2007, Caso Wagner y JNWL contra Luxemburgo (JUR 2007/147388) o la STEDH de 3 mayo 2011, Caso Négrépontis-Giannisis contra Grecia (TEDH 2011/43).

${ }^{38}$ A título ejemplificativo, pueden citarse las SSTEDH de 26 mayo 1994, Caso Keegan contra Irlanda (TEDH 1994/21) y de 22 junio 2004, Caso Pini y otros contra Rumanía (JUR 2004/178985).

${ }^{39}$ Véase la STEDH de 16 diciembre 1992, Caso Niemietz contra Alemania (TEDH 1992/77).

${ }^{40}$ Vid. la STEDH de 6 febrero 2001, Caso Bensaïd contra Reino Unido (TEDH 2001/82).

${ }^{41}$ Consúltese la STEDH de 29 abril 2002, Caso Pretty contra Reino Unido (TEDH 2002/23).

${ }^{42}$ Vid. la STEDH de 22 febrero 1994, Caso Burghartz contra Suiza (TEDH 1994/9).

${ }^{43}$ Vid. las SSTEDH de 22 octubre 1981, Caso Dudgeon contra Reino Unido (TEDH 1981/4) y de 19 febrero 1997, Caso Laskey, Jaggard y Brown contra Reino Unido (TEDH 1997/10).

${ }^{44}$ Vid. la STEDH de 7 marzo 2006, Caso Evans contra Reino Unido (TEDH 2006/19).

${ }^{45}$ En este sentido, cabe mencionar, el Caso Di Lazzaro contra Italia, núm. 31924/1996, Decisión de la Comisión de 10 julio 1997; y, las SSTEDH de 26 febrero 2002, Caso Fretté contra Francia (TEDH 2002/10) y de 22 junio 2004, Caso Pini y otros contra Rumanía (JUR 2004/178985).

${ }^{46}$ Vid. las SSTEDH de los Casos Keegan contra Irlanda (TEDH 1994/21) y Pini y otros contra Rumanía (JUR 2004/178985), antes citadas.

${ }^{47}$ Vid., entre otras, la Sentencia Fretté contra Francia, previamente citada.

${ }^{48}$ Por ejemplo, vid. la Sentencia E.B. contra Francia, antes citada.

${ }^{49}$ Aquí resultan ilustrativas las Sentencias de los Casos Marckx contra Bélgica (TEDH 1979, 2) y K. y T. contra Finlandia, núm. 25702/1994. 
41. Junto a ello, atendiendo a la doctrina sentada en el Caso Wagner ${ }^{50}$, parece desprenderse que el art. $8 \mathrm{CEDH}$ ampara la existencia de un supuesto derecho a disfrutar de la continuidad de la relación establecida a pesar de las diferencias existentes entre los ordenamientos jurídicos de los Estados implicados, lo que se acentúa en situaciones transfronterizas. Por esta razón, la STEDH de 4 octubre 2012, Caso Affaire Harroudj contra Francia (rec. 43631/2009), y la STDH de 16 diciembre 2014, Caso Chbihi Loudoudi y otros contra Bélgica (TEDH 2014/101), dejan bien sentado que no se produce infracción alguna del art. $8 \mathrm{CEDH}$ por la negativa de los Estados contratantes a constituir una adopción de un menor en situación de kafala. Esto es así toda vez que la kafala es una institución de protección de menores que tiene cabida en el Convenio de La Haya de 1996 y habida cuenta que los ordenamientos jurídicos de los Estados implicados (Francia y Bélgica, respectivamente) garantizan la continuidad de la vida familiar al equiparar esta institución de Derecho islámico con una tutela.

42. Además, no cabe la menor duda de que el interés del hijo ya adoptado ha orientado y matizado la aplicación de la excepción de orden público internacional por los Tribunales de los Estados contratantes de la Convención, de donde se desprende que las autoridades internas deberán ponderar todos los intereses en juego, si bien velando por la salvaguarda del interés superior del menor, que siempre habrá de prevalecer sobre los demás intereses concurrentes

43. Esta idea se consolida en la STEDH de 24 enero 2017, $\mathrm{n}^{\mathrm{o}}$ 25358/12 (Caso Campanelli y Paradiso contra Italia), en relación con la filiación mediante gestación subrogada, en la cual se define el concepto de familia de facto a los efectos de interpretar el art. $8 \mathrm{CEDH}^{51}$. De la citada resolución es importante destacar las siguientes deducciones:

$1^{\text {a) }} \mathrm{El}$ art. $8 \mathrm{CEDH}$ ampara el derecho que tiene una familia válidamente constituida conforme al Derecho del Estado de origen a ser respetada en el Estado de destino, de tal manera que comprende la vida privada que se instituye con el desarrollo del vínculo familiar. A tal fin, lo relevante para valorar la existencia de un vínculo familiar es la duración y la calidad del mismo y no tanto la presencia de lazos de carácter sentimental o emocional.

$2^{\mathrm{a}}$ ) Únicamente en el supuesto de peligro grave y real para el menor, el Tribunal admite la posibilidad de injerencia estatal para garantizar los derechos fundamentales de los menores.

$3^{\text {a }) ~ S i n ~ e m b a r g o, ~ l a ~ e x i s t e n c i a ~ d e ~ u n ~ v i ́ n c u l o ~ f a m i l i a r ~ — ~ e n ~ l a ~ s e n t e n c i a ~ e x a m i n a d a ~ e n t r e ~ l o s ~ p a d r e s ~}$ comitentes y el menor- habrá de ser estudiada con arreglo a las circunstancias y elementos concurrentes en cada uno de ellos, sin que, en todo caso, quepa llegar a la misma solución.

$4^{\mathrm{a}}$ ) Teniendo en cuenta lo que antecede la respuesta más adecuada no es la aplicación general y abstracta de la normativa correspondiente y del principio del interés del menor, junto con la excepción del orden público internacional. Ello, toda vez que puede conducir a soluciones nada equitativas en aquellos Estados que no contemplen o prohíban una institución, como es el caso de la filiación mediante las técnicas de maternidad subrogada. En este sentido, no hay que desconocer que el TEDH está interpretando de forma autónoma el concepto de vida familiar del art. $8 \mathrm{CEDH}$ y que, en consecuencia, los Estados contratantes tendrán que atender a esta nueva noción a la hora de resolver cada supuesto determinado.

$5^{a}$ ) En definitiva, el TEDH ha considerado que, en supuestos como el que nos ocupa, el Estado de destino no puede recurrir a la aplicación de la excepción del orden público internacional de forma generalizada para no otorgar el reconocimiento de la filiación, habida cuenta que ello supondría la vulneración del art. $8 \mathrm{CEDH}$ en relación con el principio del interés del menor, que se contempla como principio supranacional en el art. 8 de la Convención sobre los derechos del niño.

\footnotetext{
${ }^{50}$ Vid. la Sentencia Wagner y JNWL contra Luxemburgo, antes mencionada.

${ }^{51}$ Para un mayor conocimiento del tema, Vid. A.M. Ruiz Martín, "El Caso Campanelli y Paradiso ante el Tribunal Europeo de Derechos Humanos: el concepto de familia de facto y su aportación al debate de la gestación por sustitución”, Cuadernos de Derecho Transnacional, Vol. 11, nº 2, Octubre 2019, pp. 778-791.
} 


\section{Recapitulación conclusiva}

44. Teniendo en cuenta lo que antecede, resulta procedente responder a las cuestiones que se plantearon al principio de esta exposición.

45. Así, como punto de partida, habría que dilucidar si, en verdad, existe un orden público internacional europeo capaz de imponerse frente a las reglas del Derecho internacional privado y a los conceptos de Derecho sustantivo de cada Estado. Sobre el particular, de lo estudiado a lo largo de este trabajo, puede concluirse que, ciertamente, existen unos principios y valores superiores previstos en diferentes textos del Derecho de la Unión Europea y en el CEDH, que vinculan a los Estados miembros y a los Estados contratantes, como pueden ser el derecho a la libertad de circulación y residencia, a la ciudadanía europea o el derecho al respeto de la vida privada y familiar. En este punto, sirva de ejemplo, la previsión que hace el art. 10.2 CE en relación con la interpretación de los derechos fundamentales recogidos en la Carta Magna, en consonancia con los Tratados e instrumentos internacionales suscritos por España y que se encuentran en vigor en nuestro país.

46. Sin embargo, como bien apuntan Calvo Caravaca y Carrascosa González, al analizar la jurisprudencia del TJUE ${ }^{52}$, la argumentación debe plantearse en dos niveles jurídicos diferentes, sin asociar unas materias, objetivos o valores. Es decir, una cosa son los valores propios del Derecho de extranjería o del Derecho público o administrativo europeo, y otra muy distinta las materias objeto del Derecho Internacional privado. Desde esta perspectiva, lo más lógico es entender que el Derecho europeo ampara la salvaguarda de la libertad de circulación y residencia de los ciudadanos de la Unión, así como el respeto a su vida privada familiar; mientras que la cuestión de la validez de una relación jurídica de familia en el Estado de destino dependerá de la solución que contemplen las normas de Derecho Internacional privado de dichos Estados.

47. Aparte de lo anterior, la otra cuestión que se formulaba al inicio del trabajo hacía referencia a la presencia de la equidad como valor del orden público europeo, en cuya virtud fuera posible aplicar la teoría de los efectos atenuados del orden público internacional en cada caso concreto y conciliar, de este modo, realidades jurídicas dispares en orden a alcanzar una solución de justicia material.

48. $\mathrm{Al}$ respecto, en primer lugar, habría que explicar que, de la jurisprudencia examinada, tanto del TJUE como del TEDH, se desprende que, en supuestos como los que nos ocupan, y en especial, tratándose de situaciones transfronterizas en las cuales es fácil encontrarse con situaciones claudicantes, habrá que estar a las circunstancias del caso concreto, sin que quepan las respuestas generales ni en la aplicación de determinados principios, como, por ejemplo, el del interés del menor, ni tampoco de la normativa aplicable. Lo mismo cabe decir de la excepción del orden público internacional prevista en las normas de Derecho Internacional privado de los Estados de destino, respecto de la cual tampoco es posible una aplicación plena en todos los supuestos.

49. En segundo término, parece razonable entender, atendiendo a las resoluciones estudiadas, que el respeto a los derechos adquiridos y la búsqueda de soluciones equitativas ha llevado a los tribunales europeos a modular la aplicación del orden público internacional de los Estado de destino, con la finalizar de garantizar el respeto a los valores recogidos en el Derecho de la Unión Europea y en el CEDH. Ello conllevaría, como es posible advertir, no la plena eficacia en el Estado de destino de la situación jurídica concreta de Derecho de familia, sino únicamente el reconocimiento de determinados efectos que en nada conculcarían los principios y valores fundamentales que constituyen el orden público internacional del foro. Lo mismo cabría sostener si la situación no presenta vinculación con el Estado del foro.

${ }^{52}$ Vid. J. CARRASCOSA GonZÁLEZ, "Libre circulación de personas..., cit. 
50. Para concluir, del análisis de la doctrina del TJUE y del TEDH, sin ningún género de dudas se desprende que, en todo caso, el valor superior que se pretende proteger es la continuidad en el Estado de destino de la relación jurídica familiar que se ha establecido válidamente en el Estado de origen. Y esto solo es posible en virtud de la equidad. La equidad, como hemos visto en el cuerpo del trabajo, es justicia matizada o atenuada por otras virtudes, como la solidaridad, por ejemplo. Y esto es así porque, en el contexto general de las relaciones humanas y del "bien común" — es decir, del cumplimiento o aplicación de las leyes-, la justicia no puede ser contemplada aisladamente; siendo por ello que la equidad está llamada a atemperar el deber y a acomodar el derecho en cada caso concreto y solo si este así lo requiere.

51. Por tales motivos, atendiendo a la idea de que la equidad puede equipararse a la justicia en su aplicación al caso concreto, la respuesta a la pregunta que se ha formulado más arriba ha de ser positiva. Todo esto, por la importancia que supone dar cabida a la aplicación de un mecanismo similar al del orden público internacional atenuado o de proximidad en cada caso particular, siempre en orden a alcanzar una solución material justa, o equitativa, que conduzca a un objetivo final, que no es otro que la estabilidad y persistencia de las relaciones de Derecho de familia en supuestos transfronterizos. 